\title{
Mobilidade urbana: os desafios do futuro*
}

\author{
Urban mobility: the challenges of the future
}

Fernando Nunes da Silva

\section{Resumo}

As décadas que se seguiram à Segunda Guerra Mundial foram dominadas pelo domínio do automóvel na mobilidade urbana, tanto no que se refere à sua crescente importância na repartição modal, como na definição das políticas públicas e estratégias de acessibilidade. Com a primeira crise dos preços do petróleo, nos anos 1970, e a posterior consciência ambiental dos impactos negativos atribuídos ao setor dos transportes, começaram a desenhar-se outros tipos de políticas, mais orientadas pelos conceitos de intermodalidade e de coesão social, além de mais preocupadas em reduzir os impactos ambientais da mobilidade urbana. Num período em que os novos países emergentes atravessam uma fase de forte crescimento econômico e consequente aumento da motorização individual, será útil analisar essa evolução das políticas de mobilidade e retirar algumas conclusões quanto aos caminhos a prosseguir, pondo em evidência as especificidades que existem nesses países, mas também o que podem aproveitar dos ensinamentos do passado recente.

Palavras-chave: mobilidade urbana; políticas de mobilidade; países emergentes.

\begin{abstract}
The decades following the Second World War were characterized by the predominant presence of the automobile in urban mobilit $y$, both in terms of its increasing importance in the modal split, and also regarding the definition of public policies and strategies of accessibility. With the first oil crisis in the 1970s and the subsequent environmental awareness of the negative impacts of the transport sector, new policies began to be designed, guided by concept s such as intermodality and social cohesion, as well as more concerned about reducing the environment al impacts of urban mobility. In a period where the new emerging countries present a strong economic growth and a consequent increase in the motorization rate of their population, it is useful to analyze the evolution of such mobility policies and share some conclusions about the paths to follow, highlighting the specificities of those countries, and also the lessons of the recent past.
\end{abstract}

Keywords: urban mobility; mobility policies; emerging countries. 


\section{Do sonho à realidade, ou de como o automóvel passou de mito a pesadelo}

0 processo de planejamento de transportes foi orientado para o automóvel, baseado na ideologia da mobilidade irrestrita, mas normalmente limitando esta mobilidade àqueles que podem pagar os custos do transporte individual.

Eduardo A. Vasconcellos

La dépendance automobile ne trouve pas son origine dans les villes (ni dans les campagnes) mais dans le développement d'un système automobile qui n'en respecte pas les limites.

Gabriel Dupuy

Enquanto na Europa a ideologia do "tudo pelo automóvel, nada contra o automóvel", que marcou as políticas de mobilidade e transportes no pós Segunda Guerra, está claramente posta de parte e é apenas encarada como uma curiosidade científica a estudar, nos países emergentes e em desenvolvimento acelerado, a pressão das nossas classes médias e dos interesses associados ao mercado do petróleo e das grandes obras públicas continuam a determinar as opções e prioridades políticas da administração pública no sentido do favorecimento do transporte individual.

Tal como nos EUA das décadas de 1950 a 1970, o automóvel (e toda a economia que gira em torno dele) continua nesses países a ser visto como um forte motor do crescimento econômico e de acesso à mobilidade. Assim sendo, é "natural" que as políticas públicas não deixem de o privilegiar, quer no que se refere aos incentivos para a indústria de montagem de automóveis, como ao nível da construção de novas infraestruturas rodoviárias, quer ainda no controle do aumento dos preços de combustível (sempre abaixo da inflação) e na relativa estagnação ou secundarização do investimento nas redes e sistemas de transportes coletivos. De fato, parece que ainda nos encontramos na época em que, nos EUA, publicava-se o que muitos consideram já o último elogio e defesa do automóvel e da sua cultura. Aí se afirmava que "unless there is a radical change in our social and economic structure, people will continue to want and use transportation that will give them maximum freedom to move about and to choose where they live, work, or locate their businesses" (Rae apud Flink, 1975, p. 212), para logo a seguir concluir que colocar limitações artificiais ou restrições ao uso do automóvel e do transporte rodoviário, apenas conduziria à estagnação social e econômica. Desse modo, as políticas deveriam sobretudo orientar-se para responder a essa procura crescente, pois "the Road and Car together have an enormous capacity for promoting economic growth, raising standards of living and creating a good society. The challenge before us is to implement this capacity" (ibid.).

Hoje, perante os problemas associados ao aquecimento global e ao peso que o setor dos transportes tem na emissão de gases com efeito de estufa, ${ }^{1}$ o aumento do número de vítimas relacionadas com os acidentes e a poluição atmosférica atribuídos ao transporte rodoviário, ${ }^{2}$ a perda de competitividade urbana devido aos crescentes congestionamentos de tráfego, e agora, mais recentemente, aos movimentos sociais que exigem melhores transportes coletivos e mais baratos, talvez estejamos mais próximos da "mudança radical" 
de que falava Rae, do que se continuarmos a atuar segundo o modelo "predict and provi$d e$ ", que dominou os estudos e as políticas de transportes e mobilidade nos 30 anos que se seguiram à Segunda Guerra Mundial.

Todavia, por mais exemplos que se deem de como esse caminho só pode conduzir ao desastre - tanto urbanístico como social e econômico - a recusa em olhar a realidade tal como ela se apresenta nesses países e em responder com imaginação e realismo aos problemas específicos que se colocam têm falado mais forte e impedido que se avance com políticas de mobilidade mais adequadas às necessidades de deslocação da esmagadora maioria da população (grande parte sem ter sequer os meios para pagar qualquer transporte motorizado, quanto mais um automóvel!), mais interligadas e articuladas com os modelos de crescimento urbano e mais amigas do ambiente e não tão consumidoras de energia primária.

Os recentes acontecimentos no Brasil, provocados pelo anúncio (e várias tentativas) de aumento das tarifas dos transportes urbanos e metropolitanos, vieram mostrar, em toda a sua extensão, como a questão da mobilidade urbana é cada vez mais percebida como um direito de cidadania e uma exigência de equidade social, com um potencial mobilizador que vai muito para além das reivindicações tradicionais, promovidas e enquadradas pelas estruturas sindicais e partidárias habituais. Não ter entendido que, com a progressiva construção e consolidação de uma classe média (mesmo que "baixa" para os padrões europeus), as necessidades e ambições de mobilidade não poderiam continuar a ser satisfeitas com base em um modelo importado dos EUA e do Banco Mundial dos anos 1970 e 1980 onde tudo era pensado e planejado em função do automóvel privado, de acordo com o modelo "predict and provide"-, mas sim através de uma política e estratégias de promoção e favorecimento dos modos não motorizados ${ }^{3} \mathrm{e}$ dos transportes coletivos, custou caro ao governo, tanto o federal como os estaduais. A explosão de contestação social que essa questão das tarifas do transporte coletivo desencadeou - pelo que isso implicava de limitação da mobilidade para milhões de pessoas - e de como rapidamente se passou para a discussão da coerência e das prioridades a atribuir aos investimentos públicos é um primeiro sinal dos tempos que hão de vir, caso as políticas públicas de mobilidade e transportes mantenham 0 rumo seguido até aqui.

Daí o interesse em analisarmos a evolução dessa problemática na Europa, onde a força do movimento sindical do pós-guerra e as ideias e governos social-democratas e democratas-cristãos, que dominaram a cena política nas três décadas que se seguiram, conduziram ao progressivo desenvolvimento de políticas públicas de transportes e mobilidade que nunca deixaram de ter em conta 0 seu caráter social e, portanto, de se orientarem para satisfazer as necessidades básicas de deslocação da população. 0 maior peso atribuído ao transporte coletivo ou ao individual - sem que nunca se permitisse que o papel de um anulasse o do outro (foi esse o compromisso político possível) - dependeu primeiro da própria estrutura industrial e de rendimentos do país em causa e, mais tarde, já após a entrada em cena do conceito de "desenvolvimento sustentável" ${ }^{4}$ no final da década de 1980, das preocupações ambientais e de coesão social. 
A história europeia das políticas de mobilidade, neste período, é assim um percurso que começa por se maravilhar com o potencial econômico, social e cultural associado à democratização da posse e do uso do automóvel (seguindo aqui as pisadas dos EUA, ainda que com uns trinta anos de atraso), ${ }^{5}$ para depois, em resultado do próprio sucesso da motorização individual ${ }^{6}$ e da pressão dos movimentos ambientalistas, passar a abraçar políticas mais equilibradas do ponto de vista modal, onde o transporte coletivo urbano assume 0 papel estruturante de todo o sistema de transportes e no assegurar da mobilidade da grande maioria da população, mesmo aquela que possui automóvel.

Essa mudança de paradigma não se fez contudo sem resistências e sem que, em certo momento, se tentassem ainda outras soluções que não pusessem em causa de modo tão evidente o papel do automóvel na mobilidade urbana.

De fato, quando em meados dos anos 1960, Colin Buchanan (mais tarde, Sir) apresentava o seu relatório ao governo de Sua Majestade Britânica sobre o tráfego nas cidades (como foi aliás batizado o próprio relatório: Traffic in Towns), ${ }^{7}$ poucos souberam antecipar que se estava perante a constatação e demonstração de uma das mais importantes condicionantes do futuro da mobilidade urbana.

Numa época em que os fabulosos trinta anos de crescimento econômico europeu e americano do pós-guerra estavam no auge; quando outros quatro fabulosos (estes de Liverpool, os famosos Beatles) revolucionavam a música popular e ditavam os padrões da moda jovem e do seu modo de vida urbano; ${ }^{8}$ quando os ventos das revoltas juvenis contra a guerra do Vietname nos EUA, de maio de 1968 em Paris e da Primavera de Praga começavam a anunciar-se como contestação às sociedades condicionadas (fosse pela ditadura do consumismo, fosse pela do Estado), quando a produção automóvel disparava e se transformava no principal motor da economia dos países mais industrializados do Mundo, eis que um rigoroso relatório - no esteio das melhores tradições das comissões independentes do Parlamento Britânico - vinha questionar de forma inequívoca e, para a época, assaz surpreendentemente, que o futuro da mobilidade urbana não poderia assentar sobretudo no automóvel. Essa conclusão se impunha não só porque as nossas cidades não estavam preparadas para absorver todo esse tráfego, como, caso isso acontecesse, significaria uma tão profunda alteração dos nossos modos de vida, que as consequências para a vida urbana e a sociedade democrática - tal como a conhecemos hoje, isto é, baseada na delegação de poderes em representantes eleitos por sufrágio universal - seriam inimagináveis, mas certamente preocupantes.

Para quem via no automóvel o maior símbolo da moderna industrialização, o principal motor das economias mais desenvolvidas e com os maiores interesses na exploração do petróleo (então a única base para o combustível dessas "maravilhosas máquinas"), o (quase) incontestável fetiche do novo status urbano e, sem dúvida, o instrumento da democratização da mobilidade individual, tais constatações, mais que um alerta, constituíram um primeiro choque para os que, já nos distantes anos 1930, tinham afirmado, em relação ao automóvel, que "It is probable that no invention of such far reaching importance was ever diffused with such rapidity or so quickly exerted influences that ramified through the 
national culture, transforming even habits of thought and language" (Recent Social Trends in the United States, 1933, p. 172), ou ainda que "car ownership has created an 'automobile psychology'; the automobile has become a dominant influence in the life of the individual and he, in a very real sense, has become dependent on it" (ibid).

Como é frequente na história do pensamento humano e da evolução das sociedades de matriz ocidental, esse "sobressalto" começa apenas por ser partilhado por uma pequena minoria, ${ }^{9}$ dando antes origem a soluções de acomodação do automóvel no espaço urbano e por fundamentar importantes alterações nesta paisagem (dos viadutos à construção da "cidade por níveis" - de que Hong Kong e a nova cidade de Lovaina, primeiro, e o bairro da Défense, em Paris, depois, são exemplos paradigmáticos - passando pela "suburbia" de tipo americano) em vez de suscitar uma reflexão mais profunda e estratégica quanto ao devir da cidade, onde a mobilidade se afirmava progressivamente como mais um dos direitos urbanos.

No entanto, não foi preciso esperar muito tempo para se perceber que algo de mais eficaz e estratégico havia que fazer para além de se prosseguir no afã ciclópico de construir cada vez mais autoestradas e vias rápidas urbanas (mais ou menos "duras" ou amenizadas segundo o conceito de parkway) ou de providenciar imensos espaços e edifícios dedicados aos $70 \%$ do tempo em que o automóvel estava parado. A primeira crise do petróleo, logo no início dos anos 1970 (o primeiro sinal de alarme ocorreu em 1973, verificando-se então uma brutal subida dos preços do crude e a afirmação da Opep como ator essencial no condicionamento do futuro das economias industrializadas) veio colocar na ordem do dia duas questões fundamentais e que passaram a determinar toda a evolução do sistema de transportes existente: o tempo dos combustíveis baratos iria acabar e, talvez ainda mais importante, quer pelas suas implicações econômicas, quer sobretudo geopolíticas, o centro de decisão deixava de estar apenas nos países mais desenvolvidos e de cultura ocidental, para incluir também quem produzia e condicionava o mercado do chamado "ouro negro". As guerras pelo controle dessa produção, que se sucederam com uma cadência cada vez maior, aí estão para o demonstrar.

Se, por um lado, a energia que alimentava o funcionamento das sociedades modernas e, em particular, os seus sistemas de transportes e mobilidade, deixava de ser considerada um bem inesgotável e acessível, por outro lado, a constante pressão do automóvel nas cidades - derivada do crescimento exponencial da taxa de motorização ${ }^{10}$ e da progressiva transferência modal do transporte coletivo para o individual - conduzia ao surgimento de custos e impactos (associados ao congestionamento do tráfego, aos acidentes rodoviários e às emissões poluentes) cada vez mais incomportáveis e pondo em perigo o próprio funcionamento e competitividade das cidades.

0 tempo do todo-poderoso e presente automóvel começava, assim, a conhecer o seu ocaso. Tal não significaria porém que as sociedades (e os que as dirigiam, tanto política como economicamente) estivessem prontas para abandonar esse importante (e quiçá insubstituível) meio de transporte. Passados oitenta anos sobre as conclusões do relatório da comissão presidencial americana, a sua constatação de que o ser humano se tinha tornado, de certo modo, dependente do automóvel 
para a sua vida quotidiana, está mais presente que nunca, constituindo, nas sociedades mais abastadas, o principal obstáculo para que outro caminho seja percorrido. Tal situação pode encontrar alguma explicação no fato de parte significativa da população ainda não apoiar políticas demasiado restritivas ao uso do automóvel ou, nos casos onde a motorização foi apesar de tudo mais recente, ser a maioria da população constituída pela primeira geração para quem o automóvel se generalizou como modo de transporte, sendo por isso difícil aceitar, quando acabaram de aceder a este, a imposição de restrições ao seu uso. Pelo contrário, nos países de economia emergente, são as classes médias mais tradicionais e consolidadas (ou a burocracia de Estado) que dominam a opinião pública e condicionam de certo modo as políticas públicas. Como poderão essas aceitar que o Estado, que suportam financeiramente através dos seus impostos, não atribua a primazia ao modo de transporte em que se deslocam habitualmente ${ }^{11}$

Mas algo de novo é forçoso constatar. Dos encômios a um futuro assente na mobilidade satisfeita através do transporte individual, passou-se para uma consciência coletiva (aliás traduzida em vários e importantes documentos de organizações internacionais, desde as Nações Unidas ${ }^{12}$ à Organização Mundial de Saúde e à Comissão Europeia, bem como em outros tantos estudos e livros científicos) ${ }^{13}$ de que o automóvel tem de ser "domesticado" e que a mobilidade urbana tem de passar a ser assegurada com o recurso a outros modos de transporte, desde logo pelos públicos, mas também, pelos modos suaves ou ativos (andar a pé ou de bicicleta). 0 "mito" transformou-se, assim, progressivamente, num "pesadelo", para o qual há que procurar o antídoto certo de modo a poder continuar a usufruir as suas inegáveis vantagens, sem com isso pôr em causa o futuro coletivo das nossas cidades, ou mesmo do planeta que habitamos, como apontam os estudos sobre as alterações climáticas e as suas causas antropogênicas. 0 tempo da mudança chegou! Pelo menos no que diz respeito à Europa e a algumas metrópoles do continente norte-americano.

A situação dos países emergentes e em desenvolvimento é, todavia, diferente. Nesses casos, não só a indústria automóvel é um dos mais importantes motores da nova industrialização e modernização do tecido produtivo que conhecem, como as suas elites e classes médias consolidadas não concebem outro tipo de mobilidade que não seja a baseada em transporte individual. Não se trata apenas de uma questão de status e prestígio social, mas porque o próprio sistema de transportes coletivos não tem capacidade e a flexibilidade suficientes para, simultaneamente, responder a uma procura de massas (cuja dimensão se situa na ordem dos vários milhões de viagens diárias) e conseguir assegurar as condições de conforto e de atratividade que lhe permitam competir com o transporte individual.

Desse modo, tentar transpor para esses países as mesmas estratégias que as atualmente em curso nos países onde as diferenças sociais e de rendimento não são tão extremadas, onde a motorização individual ultrapassou já a fase de "deslumbramento" pelo automóvel e onde a consciência coletiva dos seus impactos propicia o desenvolvimento de políticas de mobilidade mais equilibradas e mais atentas aos problemas ambientais e à coesão social, só poderá esbarrar na oposição da 
maioria dos decisores públicos (condicionados pela forte pressão da burocracia e das classes médias) e acabar por protelar as políticas que poderão contribuir para uma progressiva inversão das tendências de investimento público massivo em infraestrutura rodoviária e deixar ao setor privado (formal ou informal) a organização e exploração da oferta do transporte público.

\section{Uma mobilidade mais amiga do ambiente e mais solidária}

Não há cidade sem movimento, nem sociedade que prescinda das interações entre os seus membros.

Una città abbandonata dall'automobile, una città senza traffico, è una città morta. ... Possiamo urlare qualunque proclama, 0 lanciare qualunque anatema: il quotidiano traffico privato è conditio sine qua non per la vita delle città.

(Cetica, 2000)

0 problema não está por isso no regresso a um qualquer passado, mais idealizado que real, onde tudo estaria ao pé de casa e onde as necessidades de transporte seriam diminutas face à autossuficiência das sociedades. Esse mito esconde na prática uma ideologia reacionária, que o progresso da humanidade desmente, apesar de todos os sobressaltos, falhanços e desastres que esse processo tem comportado. A questão que se coloca não pode ser o retornar às épocas onde só os poderosos tinham o privilégio e os meios para se deslocarem, onde as trocas econômicas eram incipientes e o tipo de trabalho definido pelo nascimento.
Todavia, o futuro da mobilidade urbana também não pode ser perspectivado como uma simples projeção de tendências observadas no passado, tal como foi usual fazer quando os modelos de transportes se limitavam a extrapolar a anterior evolução da procura e a considerar a mobilidade motorizada como ilimitável, a que era forçoso dar resposta através de mais e melhor oferta de infraestruturas e serviços. Nesse caso, não só o ponto de chegada dessas projeções talvez nem tivesse sequer condições de existir, como a destruição dos espaços urbanos, tal como hoje os conhecemos, e os impactos ambientais irreversíveis que tal acarretaria seriam os resultados intrínsecos e incontornáveis dessa dinâmica, aliás mais teórica que realista.

Ao reacionarismo do regresso a uma sociedade de características feudais, ao catastrofismo dos que não conseguem articular a modernidade com o respeito pelo ambiente, ou à inconsciência ignorante dos que consideram que tudo se haverá de resolver por uma qualquer inovação tecnológica, há que opor novos paradigmas para a mobilidade urbana.

Com efeito, já em 1995, a então designada Conferência Europeia dos Ministros dos Transportes (ECMT) definia um conjunto de instrumentos-chave, no âmbito de uma política integrada de transportes e urbanismo, visando a um desenvolvimento sustentável das mobilidades (ECMT/OCDE, 1995, pp. 147-149):

- Planejamento do uso do solo e políticas de controle do crescimento urbano, que influenciem os padrões de urbanização e incrementem a acessibilidade ao emprego, ao comércio e ser viços, e a outras atividades, sem a necessidade de recurso à deslocação em automóvel. 
- Políticas que afetem o preço dos combustíveis, a compra e o licenciamento dos automóveis, o estacionamento e a utilização das infraestruturas rodoviárias, que influenciem a concepção dos veículos, a localização das atividades, a escolha modal e o crescimento do teletrabalho.

- Medidas que façam uso da telemática para a gestão da circulação, do estacionamento e dos transportes públicos, afim de aumentar a eficiência dos sistemas de deslocações urbanas e promover a mudança do automóvel para os outros modos de transporte.

- Políticas que responsabilizem os empregadores pelo planejamento das deslocações pendulares, de forma a reduzir os picos de tráfego e potenciar uma repartição modal mais favorável ao transporte coletivo.

- Políticas respeitantes ao financiamento, à privatização e ao uso dos sistemas de informação e de promoção (marketing) que aumentem a eficiência e a atratividade do transporte público.

- Medidas de implementação de "zonas livres de automóveis", de moderação da circulação e de prioridade ao pedestre, que fomentem a caminhada e o uso da bicicleta, reduzindo os riscos para a utilização desses modos de transporte e promovendo a atratividade das cidades.

- Medidas que promovam a criação de zonas de intercâmbio de mercadorias e o uso de veículos de distribuição adaptados à cidade, "a fim de adequar a logística às condições urbanas" (Nunes da Silva, 2005, pp. 298-299).

Para que essa nossa forma de nos deslocarmos se possa desenvolver e vir a se consubstanciar numa mobilidade mais sustentável, isto é, mais amiga do ambiente, mais equitativa do ponto de vista social e economicamente mais eficiente, há quatro estratégias que se afiguram imprescindíveis concretizar:

1) Promover a intermodalidade: na sociedade urbana atual, a complexidade e diversidade dos modos de vida e das necessidades de deslocação exigem não só que se utilizem todos os modos de transporte disponíveis (dos motorizados aos suaves, dos públicos aos privados, dos individuais aos coletivos), como que a passagem de um modo para outro se processe sem atritos, isto é, que os vários modos de transporte estejam articulados entre si e que as mudanças entre eles não sejam penalizadoras para quem se desloca, quer em tempos de espera e condições físicas em que essa mudança se processa, quer em termos de custo. Tal exige uma eficiente integração funcional e tarifária entre os vários modos de transporte coletivo e sistemas que promovam e facilitem a utilização combinada de transportes individuais (motorizados ou não) e coletivos, públicos ou partilhados.

2) Favorecer uma repartição mais amiga do ambiente: diante do presente domínio do automóvel, é forçoso reequilibrar a repartição modal. Desde logo favorecendo o transporte coletivo, não mais concebido como o modo de transporte dos que não têm ou não podem circular em automóvel, mas como o modo mais eficaz de movimentar maiores procuras e diminuir o espaço urbano afetado às deslocações motorizadas. Mas também através da reabilitação do andar a pé e de bicicleta, criando condições favoráveis e seguras para esse tipo de deslocação e eliminando os inúmeros obstáculos que se foram criando nas nossas cidades a esses meios de transporte, desde logo ao nível dos passeios e percursos pedestres. 
3) Melhorar as condições de segurança e fluidez do tráfego: pensar que, diante do peso que o automóvel tem hoje nas deslocações urbanas, será suficiente atuar na promoção de alternativas ao seu uso e na introdução de restrições do seu acesso a zonas cada vez mais extensas da cidade, é votar essa políticas ao fracasso, tanto mais rápido e dramático (porque inibidor da implementação de soluções exequíveis por muito mais tempo) quanto maior for a força da sociedade civil em democracia. Assim, ao mesmo tempo que se promovem alternativas e condicionantes ao uso abusivo do automóvel, há que melhorar significativamente a gestão do tráfego urbano, para o que se dispõe já de um poderoso e eficaz conjunto de soluções e tecnologias, desde a telemática à gestão centralizada do tráfego, passando pela informação pública disponibilizada em tempo real.

4 ) Articular transportes e usos do solo: as necessidades de deslocação (tanto de pessoas como de bens) resultam da dispersão das atividades no espaço urbano. Atuar no sistema de transportes e mobilidade sem o fazer igualmente ao nível do urbanismo e do ordenamento do território, é construir por um lado e destruir por outro. Desenvolver políticas de habitação e criar condições para o retorno à cidade-centro (onde as redes de transporte coletivo são mais densas e onde as distâncias a percorrer são compatíveis com a utilização dos modos suaves); fomentar a mistura de usos do solo complementares e consolidar ou promover novas centralidades urbanas (nomeadamente através da densificação urbana em torno das estações de comboio e metrô, e das principais interfaces); recuperar a rua como espaço de convívio, coesão social e urbanidade; desenvolver projetos de transportes em sítio próprio, associados a políticas de reabilitação urbana e qualificação do espaço público; implementar políticas de estacionamento articuladas com a oferta em transporte público, são alguns exemplos de como se pode promover a desejável simbiose entre políticas de mobilidade e urbanísticas.

As principais diferenças que devem existir na aplicação dessas estratégias, quando se lida com países mais desenvolvidos ou com países emergentes, radicam mais no seu doseamento - função sobretudo da sua composição social, do seu estádio sociocultural e da sua estrutura econômica e organização do espaço urbano - do que no "apagamento" de uma área de intervenção em favor de outra.

Não se nega que os desafios que o futuro da mobilidade urbana coloca são complexos, nem que os problemas, que urge resolver nesse domínio, exigem modos de atuar e meios que nem sempre são fáceis de instituir e mobilizar. Mas o que sabemos é que o caminho trilhado até agora só pode conduzir ao agravar dos problemas ambientais, urbanos e sociais. Sabemos também que outros conseguiram, senão superá-los completamente, pelo menos inverter a tendência e pôr em prática soluções inovadoras e socialmente aceites, que apontam para futuros mais promissores, qualquer que seja a latitude que estivermos a considerar. 0 principal problema que tiveram de enfrentar foi o dos "poderes instituídos" e vencer a "preguiça mental" em analisar os problemas nas suas diferentes vertentes e pensar soluções que melhor respondam aos objetivos a atingir. Isso, se bem que difícil, está certamente ao alcance dos conhecimentos e das tecnologias de que hoje dispomos! 
Como sintetizou de modo sublime um colega de profissão e atento observador dos desafios que hoje se colocam às nossas cidades, "embora seja comum a ideia de que as cidades se tornaram congestionadas, poluídas, inseguras e desiguais, o fluxo contínuo de pessoas que trocam as áreas rurais por áreas urbanas, em busca de melhores oportunidades, demonstra que a vida nas urbes é uma proposta de valor sem concorrência", para depois concluir que "a única alternativa à cidade é uma cidade melhor" (Mendes, 2011).

\section{Fernando Nunes da Silva}

Professor catedrático do Instituto Superior Técnico e investigador do Centro de Sistemas Urbanos e Regionais - Cesur, da Universidade de Lisboa. Vereador da Mobilidade na CM de Lisboa. Lisboa, Portugal.

fnsilva@ist.utl.pt

\section{Notas}

(*) Este texto reflete, sobretudo, uma prática profissional de várias décadas no domínio dos transportes e da mobilidade urbana, a que se somaram, recentemente, quatro anos como membro do executivo municipal de Lisboa, enquanto vereador e secretário da Mobilidade. Para uma melhor fundamentação das ideias e reflexões aqui expressas, sugere-se a leitura dos seguintes textos publicados pelo autor: "Políticas Urbanas para uma Mobilidade Sustentável" (GeolNova, n. 7, Lisboa, 2003); "Políticas Urbanas para uma Mobilidade Sustentável" (GeolNova, n. 10, Lisboa, 2004); "Transportes, Mobilidade e Ambiente: os usos, os costumes e os desafios para o século XXI" (in: Soczka, Luís, org., Contextos Humanos e Psicologia Ambiental", Lisboa, Fundação Calouste Gulbenkian, 2005); Transportes e Ambiente. Indicadores de Integração (com M. Beja e S. Castelo, Lisboa, Ed. Direcção Geral do Ambiente, Ministério do Ambiente, 1999).

(1) Entre 1950 e 2005, o volume mundial de emissões de dióxido de carbono, associado à queima de combustíveis fósseis (onde o setor dos transportes tem uma quota importante), passou de 1,6 para 7,2 milhões de toneladas (Sawin, 2005).

(2) De acordo com um estudo do Banco Mundial, publicado em 2000, estima-se que o número de mortes prematuras, associado à poluição atmosférica nas áreas urbanas, atinja um valor médio de 1,8 milhões de pessoas por ano, até 2020 , dos quais mais de $60 \%$ das mortes ocorrerão na China, Índia e América Latina ("Air Polluyion Still a Problem”, Gary Gardner). Por sua vez, o número de vítimas em acidentes rodoviários é hoje superior a 300 mil mortes e 8 milhões de feridos. ("Indicadores do Desenvolvimento Mundial”, Banco Mundial). 
(3) Sobretudo nas áreas centrais e nos bairros residenciais periféricos, para as deslocações de curta distância no início e no fim de suas cadeias. Note-se ainda que, segundo estudos realizados, no final dos anos 1980 no Brasil, a percentagem de pessoas que se deslocavam a pé para o trabalho se situava na ordem dos $60 \%$, para os agregados familiares com uma renda mensal inferior a 500 US\$ (Vasconcellos, 2000, p. 50).

(4) O conceito de desenvolvimento sustentável encontrou a sua consagração mundial com a publicação do livro/relatório "Our Common Future”, em 1987, pela Comissão Mundial para o Ambiente e o Desenvolvimento (World Commission on Environment and Development), das Nações Unidas, o qual ficaria conhecido pelo nome da sua responsável, a Sra. Gro Brundtland.

(5) O desenvolvimento do setor automóvel nos EUA teve, para além da política do combustível barato e dos apoios ao desenvolvimento da sua indústria, um forte incentivo a partir da publicação do "Federal Highway Act" e do "Highway Revenue Act", ambos de 1956, que não só estipulavam a construção de mais de $66 \mathrm{mil} \mathrm{km}$ de autoestradas e vias rápidas pelo país, como atribuía a esse programa uma porcentagem da receita da venda de combustiveis e pneus, uma vez que o Estado Federal suportaria 90\% do custo de construção dessas novas rodovias. Como refere Vukan R. Vuchic (1999, p. 96), ao analisar os efeitos dessa legislação, "the Federal Highway Acts of 1956 were aimed not at creating an optimal transportati on system that utilizes a coordinated set of modes, but rather gave an enormous boost to one mode only - the highway (automobile and truck), thus greatly reducing any opportunity to achieve a balanced intermodal system".

Ora foi exatamente esse tipo de política pública seguido nos países europeus menos desenvolvidos, sobretudo após o alargamento da União Europeia na segunda metade da década de 1980, com o consequente aumento das transferências de fundos comunitários de apoio para esses países. Só para Portugal esse montante terá ascendido a € 27 mil milhões.

(6) Nos designados "trinta anos de ouro" que se seguiram à Segunda Guerra Mundial, em que a economia europeia não deixou de crescer continuadamente e a distribuição dos rendimentos foi a mais equitativa de sempre, a taxa de motorização passou de cerca de 100 veículos por mil habitantes, para mais de 500 no início da década de 1990 (ODCE, CEMT, 1995), tendo vindo a estabilizar depois dessa data.

(7) Traffic in Towns, Her Majesty's Stationeri Office (London, 1963).

(8) Fez agora, 23 de março, 50 anos que o seu primeiro grande êxito foi editado, lançando-os numa das mais impressionantes e proveitosas carreiras no mundo da música popular.

(9) Com efeito, até o próprio relatório Buchanan, como viria a ficar conhecido, apesar de todas as críticas e prognósticos negativos quanto ao futuro da sociedade do automóvel, não deixava de apontar medidas de minimização dos seus impactos na cidade e de formular propostas para a sua adaptação às crescentes necessidades de espaço consagradas ao tráfego automóvel.

(10) Só para se ter uma ideia do que foi o crescimento exponencial da produção de automóveis no mundo, atente-se ao fato de que, em 1950, o número de veículos produzidos se situava nos 8 milhões, enquanto, em 2004, atingia os 44,1 milhões (cf. American Automobile Manufactures Association). Por outro lado, a taxa de motorização dos países mais desenvolvidos do mundo atingia ou ultrapassava já os 500 veículos/mil habitantes no fim do século XX.

(11) “O processo de decisão em transportes, além de ser controlado por elites políticas e econômicas, favorece as classes médias, que têm instrumentos diretos e indiretos para exercer a sua influência. O principal canal para esse exercício é formado pela tecnocracia e a burocracia, que são as classes médias no poder" (Vasconcellos, 2000, p. 172). 
(12) Sobretudo após a Conferência do Rio de Janeiro sobre Ambiente e Desenvolvimento, de 1992, e a celebração do Protocolo de Quioto em 1997.

(13) Só para referir alguns dos que marcaram o pensamento nesse domínio, citem-se, a título de exemplo, Transports, contraintes climatiques \& pollutions, de Giséle Escourrou (publicado em 1996 pela Editora Sedes de Paris) - constituindo uma das primeiras obras que sistematiza as relações e a contribuição dos transportes para as alterações climáticas -, e o que veio a tornarse a principal referência na reflexão sobre a sustentabilidade no domínio dos transportes e da mobilidade urbana: Sustainability and Cities. Overcoming Automobile Dependence, de Peter Newman e Jeffrey Kenworthy (publicado em 1999 pela Island Press, em Nova York).

\section{Referências}

CETICA, P. P. (2000). Estetica del Traffico. Milão, Editori Associati.

DUPUY, G. (1999). La dépendance automobile. Symptômes, analyses, diagnostic, traitements. Paris, Anthropos.

ECMT/OCDE (1995). Urban travel and sustainable development. Paris, CEMT/OCDE.

FLINK, J. J. (1975). The Car Culture. MIT Press.

MENDES, J. F. G. (2011). O futuro das cidades. Coimbra, Minerva.

NUNES DA SILVA, F. (2005). "Transportes, mobilidade e ambiente: os usos, os costumes e os desafios para o século XXI". In: SOCZKA, L. (org.). Contextos humanos e psicologia ambiental. Lisboa, Fundação Calouste Gulbenkian.

Recent Social Trends in the United States (1933). Report of the President's Research Commitiee on Social Trends. Nova York e Londres, McGraw-Hill.

SAWIN, J. L. (2005). Climate Change Indicators on the Rise. Worldwatch Institute Vital Signs.

VASCONCELLOS, E. A. (2000). Transporte urbano nos países em desenvolvimento. Reflexões e propostas. São Paulo, Annablume.

VUCHIC, V. R. (1999). Transportation for Livable Cities. New Brunswick, NJ, Rutgers.

Texto recebido em 4/nov/2010

Texto aprovado em 15/dez/2010 